\title{
DETERMINANTES DA DECISÃO DE COMPRA DA BAIXA RENDA
}

DETERMINANTS OF THE LOW INCOME PURCHASE DECISION

Recebido em 27.01.2018. Aprovado em 31.01.2018

Avaliado pelo sistema double blind review

DOI: http://dx.doi.org/10.12712/rpca.v12i1.1199

\section{Jorge Cleber Pereira da Silva}

Universidade Federal do Piauí (UFPI), Teresina/PI, BRASIL

jorgecleberr@gmail.com

\section{Alexandre Rabêlo Neto}

Universidade Federal do Piauí (UFPI), Teresina/PI, BRASIL

alexandrenaka@hotmail.com

\section{Resumo}

O aumento do poder aquisitivo das famílias de baixa renda transformou esse público em um mercado atraente para as empresas de vários segmentos, provocando, deste modo, demandas por pesquisas empíricas sobre a inclusão pelo consumo. Diante disso, este artigo analisou as variáveis influenciadoras do processo de decisão de compra dos consumidores de baixa renda. Trata-se de pesquisa quantitativa, descritiva transversal, do tipo survey. Para a coleta dos dados utilizou-se questionário fechado aplicado a 1.000 respondentes, consumidores de baixa renda. Para a análise dos dados foram utilizadas técnicas de análise multivariadas e modelagem de equações estruturais. O modelo estrutural analisado mostrou que preferência por locais de compra e preferências por marcas são antecedentes da decisão de compra do consumidor de baixa renda.

Palavras-chave: Consumo. Baixa Renda. Decisão de Compra.

\section{Abstract}

The increase in the purchasing power of low-income households has made this public an attractive market for multi-segment companies, thus provoking demands for empirical research on inclusion by consumption. Therefore, this article analyzed the variables influencing the purchasing decision process of low income consumers. This is a quantitative, descriptive cross-sectional survey of the survey type. To collect the data, a closed questionnaire was applied to 1000 respondents, low-income consumers. For the data analysis, multivariate analysis techniques and modeling of structural equations were used. The structural model analyzed showed that preference for places of purchase and preferences for brands are antecedents of the purchase decision of lowincome consumers.

Keywords: Consumption. Low Income. Buying Decision. 


\section{Introdução}

Segundo o CCEB - Critério de Classificação Econômica Brasil (ABEP, 2011), os indivíduos de baixa renda no Brasil integram as classe C, D e E. São pessoas que vivem com renda familiar abaixo de $\mathrm{R} \$ 1.459,00$ (C1, C2, D e E) e representam aproximadamente 78\% da população do país, o equivalente a 148 milhões de pessoas (PEREZ; BAIRON, 2013). É diante disso que se afirma que a "base da pirâmide" (PRAHALAD, 2005) tornou-se alvo de estratégias de marketing para as empresas e como consequência do aumento do consumo das classes C, D e E, observa-se um aumento na demanda por pesquisas empíricas sobre a inclusão pelo consumo.

Engel, Blackwell e Miniard (2009) afirmam que o conhecimento acerca das variáveis que influenciam o comportamento de compra é importante para que os empresários qualifiquem seus produtos/serviços e oriente suas ofertas para o mercado, uma vez que a decisão de compra considera efetivamente os desejos e as necessidades do consumidor. Diante do exposto, tem-se o seguinte problema: Que variáveis influenciam a decisão de compra do consumidor de baixa renda?

O presente artigo teve como objetivo geral: Analisar o perfil do consumidor de baixa renda através das variáveis que influenciam o comportamento de compra. E, como objetivos específicos: 1) identificar as necessidades e as tendências do mercado a partir do perfil dos consumidores de baixa renda; 2) verificar a importância que se tem dada às características dos consumidores de baixa renda por parte dos empresários; 3) perceber a natureza das estratégias de mercado voltadas para o consumidor de baixa renda; e 4) verificar as relações entre os antecedentes conforme o modelo adaptado de Silva (2008) e Rabêlo Neto (2011) que influenciam os consumidores de baixa renda.

O mercado de baixa renda tornou-se tema de grande importância ao redor do mundo, e o Brasil não constitui exceção. Segundo a Associação Paulista de Fundações (2015), a renda familiar média dos 25\% mais pobres foi a que mais cresceu na última década. Assim, a relevância do tema proposto dá-se pelo crescimento do poder de compra dos consumidores de baixa renda, uma vez que isso tem provocado o interesse dos empresários em oferecer produtos e serviços voltados para atender às necessidades desse público, ou oferecer oportunidades que permitam que esses consumidores tenham acesso a determinados produtos e serviços antes reservados para consumidores das classes A e B.

\section{Consumidor de baixa renda}

A posição relativa dos membros de uma sociedade, de modo que uma posição mais alta implica um status mais alto em relação às pessoas da classe mais baixa, é denominada classe social (SHETH; MITTAL; NEWMAN, 2008). Deste modo, a compreensão do desenvolvimento das classes sociais é relevante para entender o consumo, uma vez que a capacidade de compra do consumidor é determinada pela sua classe social (ENGEL; BLAKWELL; MINIARD, 2009).

Nessa linha de pensamento, Dias (2003) afirma que o estudo das classes socioeconômicas é relevante por permitir agrupar as pessoas em estratos que combinam fatores que suscitam valores, interesses e comportamento análogos entre os membros de determinada classe. Segundo o autor, o Critério Brasil utiliza o seu sistema de classificação por pontuação empregada nos critérios anteriores, mas atualizou a composição das planilhas visando a um melhor reflexo do potencial de consumo do brasileiro. Com isso, a classificação socioeconômica do Brasil foi estratificada em cinco classes, sendo que as duas de maior poder aquisitivo foram estratificadas em A1e A2, B1 e B2.

De acordo com a Associação Brasileira de Empresas de Pesquisa (ABEP), o Critério de Classificação Econômica Brasil (CCEB) foi criado visando à definição de grandes classes que atendam às necessidades de segmentação e não pode satisfazer todos os usuários em todas as circunstâncias, além de não ser suficiente para uma boa classificação em casos de pesquisas qualitativas. Diante disso a Associação recomenda que os empresários obtenham o máximo de informações sobre os consumidores, incluindo o comportamento de compra, preferências e interesses, hábitos de lazer, hobbies e até características de personalidade (ABEP, 2011).

Segundo Stefano, Santana e Onaga (2008), a estabilidade e o crescimento econômico acima dos $4 \%$ ao ano, a facilidade de acesso aos vários meios de comunicação e o acesso ao crédito ampliaram o consumo em todas as classes, principalmente entre as "menos favorecidas". Deste modo, a tendência mais significativa é o crescimento da classe $\mathrm{C}$, fato que o número de pessoas na base da pirâmide brasileira.

Embora seja uma população possuidora de renda pouco abundante, a baixa renda é um mercado consumidor em ascensão (PARENTE; LIMEIRA; 
BARKI, 2008), devido ao seu poder de consumo, se for considerada a renda, multiplicada pelo tamanho da população desse grupo social.

Historicamente, a influência da renda nos padrões de consumo é enaltecida, pois ao longo do curso da humanidade, a pobreza tem sido a regra e a riqueza a exceção. As sociedades no passado eram chamadas afluentes mesmo quando suas classes dominantes aproveitavam a fartura e o luxo, contrapondo a grande maioria da população que lutava pela mera subsistência (MATSUYAMA, 2002). Do ponto de vista das unidades familiares, as diferenças de renda domiciliar constituem $\mathrm{o}$ fator determinante $\mathrm{da}$ expansão ou não da variedade de compra de bens de uma família (MATSUYAMA, 2002).

$\mathrm{Na}$ verdade, os limites máximos do consumo são definidos pelos recursos financeiros, especificamente pela renda da unidade familiar, suas poupanças e dívidas (REDMOND, 2001). Todavia, o consumo é uma consequência e o desejo humano para algo tangível ou intangível é sua causa. Se o desejo humano pode ser ilimitado, seu consumo é limitado somente pelos recursos financeiros. Em síntese, enquanto os desejos materiais do homem parecem insaciáveis, os recursos para atendê-los permanecem escassos (ROSSETTI, 1991).

Basicamente, os recursos econômicos são oriundos da renda individual ou familiar. Define-se renda como o dinheiro proveniente tanto de salários e remunerações quanto de recebimentos de juros e assistência social (KOTLER; KELLER, 2006). Neste sentido, a escolha de um produto ou serviço é extremamente afetada pelas circunstâncias econômicas do consumidor: sua renda disponível (nível, estabilidade e padrão de tempo), suas economias e bens, seus débitos, sua capacidade de endividamento e sua atitude em relação a gastar versus economizar.

Logo, entende-se que a limitação de recursos econômicos ante o caráter ilimitado das necessidades, força as famílias a distribuírem sua receita entre certos consumos e em quantidades determinadas (PINTO; FREDES; MARINHO, 1983). As decisões decorrentes dessa alocação da renda formam o orçamento familiar.

No que tange aos estudos sobre o consumo, observase que os consumidores de baixa renda demonstram algumas peculiaridades devido às restrições de orçamento (PARENTE; SILVA, 2007). O uso de crédito é essencial na vida dos consumidores de baixa renda por se tratar do único meio de se obter acesso aos bens de consumo, a escolha do local de compra é outro fator importante, onde muitas emoções podem ser experimentadas, desde prazer e alegria até humilhação e vergonha (ROCHA; SILVA, 2008).

A marca dos produtos, por sua vez, é vista como sinal de qualidade e de hierarquia social, significando e ressignificando a identidade do consumidor, devendo apresentar alto desempenho e durabilidade de modo a atrair uma base alargada de consumidores (KELLER, 1993; LOURO, 2000; ROPER et al., 2013). Ainda no elemento marca, Spink (2012) informa que ela serve como um elemento legitimador das posições perseguidas pelos consumidores, sendo um elemento capaz de torná-lo ávido por novas experiências de consumo. Nesse sentido, uma marca é entendida como de confiança quando cumpre aquilo que propõe no seu posicionamento (BOECKER et al., 2009).

A escolha das lojas está ligada ao bom atendimento (BARROS; ROCHA, 2007) e, quanto ao significado dos bens, observa-se que os que são considerados mais importantes são: casa, eletrônicos, eletrodomésticos e móveis (CASTILHOS, 2007).

Baker e Cameron (1996) acrescenta que locais de compra requintados afetam na percepção de passagem do tempo pelo consumidor, levando-o a permanecer mais tempo no ambiente de loja e dando azo ao aumento dos ganhos financeiros da empresa em razão da possibilidade de compra. No contexto das compras rotineiras, o consumidor de baixa renda escolhem os ambientes em razão da variação da procura (SANTOS, 2009) ou em razão dos hábitos familiares adquiridos e da possibilidade de baixa aglomeração de pessoas nesses ambientes de loja (EROGLY; MACHLEIT, 1990).

De acordo com Solomon (2008), os consumidores percebem diferenças em produtos e lojas adequandoos de acordo com as classes sociais, sendo que os consumidores da classe trabalhadora durante seu processo de compra costumam avaliar os produtos em termos mais utilitários e são menos inclinados a experimentar novos produtos e estilos. Por outro lado, segundo o autor, consumidores mais afluentes residentes no subúrbio tendem a se preocupar com a aparência e a imagem física. $\mathrm{O}$ autor ressalta que a procura por bens e serviços por parte dos consumidores depende tanto da possibilidade de 
comprar quanto da disposição para comprar, e que o tipo de estrutura de classe hierárquica é um fator determinante ao acesso das pessoas a produtos e serviços. Ao analisar a classe social de um indivíduo pode-se considerar uma série de informações, sendo ocupação e renda as duas mais importantes seguidas da educação, que está intimamente relacionada com a renda e a ocupação (SOLOMON, 2008).

No tocante ao potencial do comportamento dos consumidores baixa renda, de acordo com Parente (2000), as empresas geralmente não percebem ou não compreendem adequadamente as necessidades desse segmento e as características peculiares do consumidor. Para o autor, apesar do sucesso de alguns segmentos, observa-se que essas novas propostas ainda não possuem um valor compatível coma as expectativas do mercado de baixa renda.

Para que as empresas alcancem sucesso no segmento de baixa renda devem desenvolver estratégias de mercado que reconheçam as aspirações desse consumidor de modo a despertar o sentimento de inclusão em estratos sociais mais elevados. Nesse sentido, Rocha e Silva (2008) ensinam que algumas estratégias de marketing podem ser adotadas para os consumidores de baixa renda por meio de enfoques alternativos nas características do produto, no apreçamento, nos canais de distribuição ou nas comunicações.

O nível de renda, para Parente e Silva (2007), é um importante corte que influencia a composição do orçamento. Famílias mais pobres investem todos os seus recursos na satisfação das necessidades vitais: comer e, em uma escala menor, morar e vestir.

Nessa mesma linha de pensamento, Pinto, Fredes e Marinho (1983) afirmam que quando os recursos familiares aumentam, o consumo de alimentos aumenta quantitativa e qualitativamente, sendo substituídos os produtos mais baratos e volumosos por outros mais selecionados e caros (leite, carnes, frutas, etc.), até chegar-se a um limite máximo, a partir do qual se estabiliza o consumo de alimentos.

\section{Comportamento do consumidor}

Solomon (2014) afirma que o comportamento do consumidor envolve uma vasta área, sendo um estudo dos processos envolvidos quando indivíduos ou grupos selecionam, compram, usam ou descartam produtos ou serviços, ideias ou experiências para satisfazer necessidades e desejos. Por sua vez, Engel, Blackwell e Miniard (2009) afirmam que o comportamento do consumidor está relacionado às atividades de adquirir, consumir e dispor de produtos e serviços, abrangendo os processos decisórios de compra que antecedem e sucedem o ato de consumir.

Investigar todos os aspectos que envolvem o ambiente do consumidor pode, por exemplo, gerar insights para a criação de novos produtos ou para a adequação de produtos já existentes, além de estabelecer novos padrões para um melhor atendimento. Assim, é importante a compreensão do comportamento do consumidor, pois o mesmo não é conhecedor de seus motivos mais profundos ou daquilo que pode influenciá-lo na opção por um produto ou serviço. Outra perspectiva epistemológica define que o comportamento do consumidor como sendo o conjunto de atividades físicas e mentais realizadas por clientes de bens de consumo que resultam em decisões e ações, de como buscar, escolher, adquirir e utilizar produtos e serviços para satisfazer uma necessidade latente (EHRENBERG; GOODHART; BARWISE, 1990).

Samara e Morsch (2005) afirmam que o comportamento do consumidor caracteriza-se como processo e, desta forma trata-se de um conjunto de estágios que envolvem a seleção, a compra, o uso ou a disposição de produtos, ideias ou experiências para satisfazer necessidades e desejos. É contínuo, não se limitando apenas ao momento da compra, quando a troca se efetiva. Embora a troca seja a essência do marketing, o entendimento mais amplo compreende todo o processo de consumo, o que inclui os aspectos que influenciam o consumidor antes, durante e depois da compra.

Os autores reforçam a necessidade de entender o consumidor, diante a necessidade de entender o ambiente onde ele está inserido, que inclui estudos sobre demografia, grupos de influência, motivação, atitudes, mudanças de necessidades e desejos, além de novos estilos de vida e novos padrões de vida. Investigar todos os aspectos que envolvem o ambiente do consumidor pode, por exemplo, gerar insights para a criação de novos produtos ou para a adequação de produtos já existentes, além de estabelecer novos padrões para um melhor atendimento (ENGEL; BLACKWELL; MINIARD, 2009).

Diante disso, o comportamento de compra do consumidor representa um dos elementos essenciais da gestão estratégica de qualquer empresa. É, por 
isso, fundamental que a empresa conheça os seus públicos de consumidores atuais e potenciais, seus comportamentos, atitudes e processos de escolha, para que possa adequar as suas atividades de gestão e fornecer a melhor resposta às solicitações dos mercados onde opera. Compete aos profissionais de marketing a tarefa de identificar as informações necessárias sobre o consumidor para poder dar a sustentabilidade necessária às suas decisões tendo como objetivo central a sua satisfação e/ou fidelização.

\section{Processo de Decisão de Compra}

Existem três variáveis que estão diretamente relacionadas ao comportamento do consumidor e que determinam como ocorre a aquisição de um bem ou serviço. Para Zeithaml e Bitner (2003) elas compreendem: o que comprar, por que comprar, onde comprar.

Mudanças sociais, tecnológicas e econômicas, ocorridas nos últimos tempos, foram fatores responsáveis por um novo indivíduo consumidor e cliente diferente, apresentando necessidades, desejos e estilos de vida que demandam, cada vez mais, produtos e serviços com qualidade e valor extra.

Dias (2003), observa que as empresas podem utilizarse de novas técnicas de pesquisa e tecnologias de um banco de dados, para capturar e tratar, de uma maneira mais abrangente, as informações sobre o cliente, entendendo as suas necessidades individuais que serão utilizadas na criação de programas de comunicação, pertinentes a cada indivíduo ou organização.

\section{Modelo de cinco estágios do processo de compra do consumidor}

Existe um modelo de cinco estágios do processo de compra típico em que o consumidor passa por cinco estágios: reconhecimento do problema, busca de informações, avaliação de alternativas, decisão de compra e comportamento pós-compra (KOTLER, 1995). Claramente, o processo de compra iniciase muito antes da compra real e tem consequências posteriores. $\mathrm{O}$ modelo da Figura 1 considera que os consumidores passam, sequencialmente, por todos os cinco estágios para comprar um produto. Mas este não é o caso, principalmente para as compras de baixo envolvimento. Os consumidores podem alternar ou inverter alguns estágios.
Figura 1. Cinco estágios do processo de decisão de compra

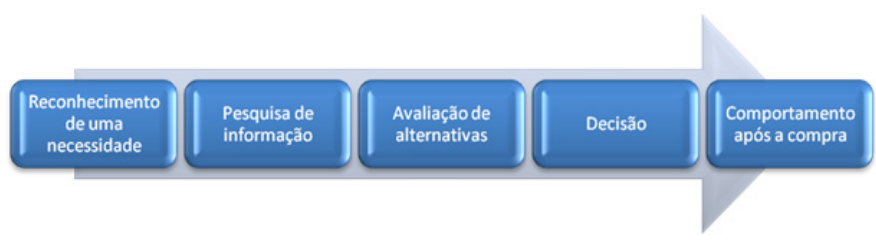

Fonte: Kotler (1995).

\section{Modelo geral de tomada de decisão do consumidor}

Conforme Engel, Blackwell e Miniard e (2009) os consumidores normalmente passam por sete estágios maiores de tomada de decisão, conforme Figura 2.

Figura 2 . Modelo geral do processo de decisão do consumidor

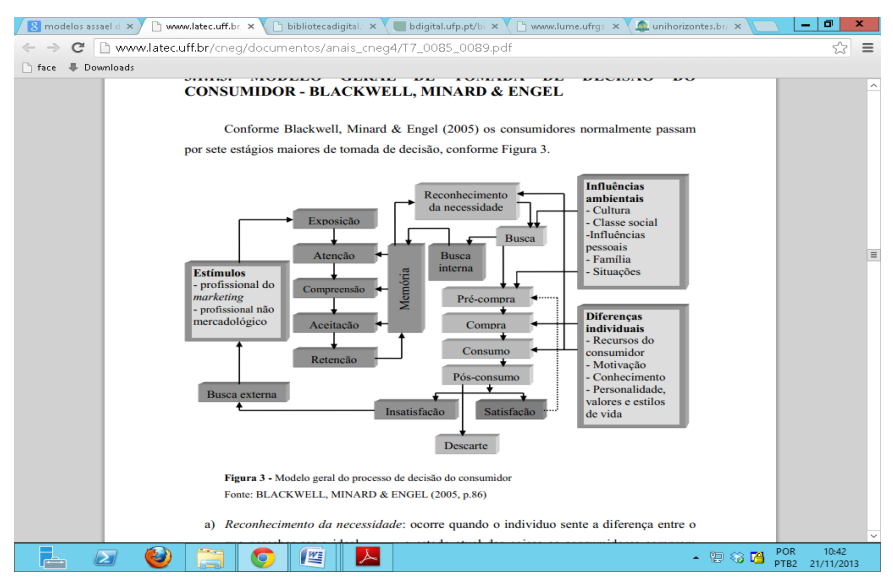

Fonte: Engel, Blackwell e Miniard (2009, p. 86)

a) Reconhecimento da necessidade: os consumidores compram coisas quando acreditam que a habilidade do produto em solucionar problemas vale mais que o custo de comprá-lo, fazendo do reconhecimento de uma necessidade não satisfeita o primeiro passo da venda de um produto.

b) Busca de informações: uma vez que ocorre o reconhecimento da necessidade, os consumidores começam a buscar informações e soluções para satisfazer as suas necessidades não atendidas. A busca pode ser interna, recuperando o conhecimento na memória ou, talvez nas tendências genéticas, ou ela pode ser externa, coletando informações entre os pares, familiares e no mercado. 
c) Avaliação de alternativa pré-compra: neste estagio, os consumidores buscam resposta para questões como "Quais são as minhas opções?” e "Qual é a melhor entre elas?" quando comparam contrastam e selecionam a partir de vários produtos ou serviços. Os consumidores comparam o que conhecem sobre diferentes produtos e marcas com o que consideram mais importantes e começam a estreitar o campo de alternativas antes de finalmente resolver comprar umas delas.

d) Compra: depois de se decidir sobre a compra, os consumidores passam por duas fases. $\mathrm{Na}$ primeira eles escolhem um vendedor em vez de outro (ou qualquer outra forma de varejo como catálogos). A segunda fase envolve escolhas dentro da loja influenciadas pelo vendedor, pelas vitrines, meios eletrônicos e propagandas no ponto de venda.

e) Consumo: feita a compra e de posse do produto, o consumo pode ocorrer tanto imediatamente como num momento posterior. A forma como o produto é utilizado pelos consumidores também afeta quão satisfeito eles estão com as compras e quando provavelmente vão comprar essa marca ou produto novamente.

f)Avaliaçãopós-consumo:oconsumidorexperimenta a sensação de satisfação ou insatisfação. A satisfação ocorre quando a performance percebida confirma ou ultrapassa as expectativas dos consumidores; quando experiências e performance frustram expectativas, a insatisfação ocorre. As emoções desempenham papel na avaliação de um produto ou transação.

g) Descarte: é o último estágio no modelo do processo de decisão do consumidor. Os consumidores têm várias opções, incluindo descarte completo, reciclagem ou revenda.

Compreendendo os estágios dentro do mapa de tomada de decisão do consumidor, profissionais de marketing podem descobrir as pessoas compram, ou não, produtos e fazer com que essas pessoas comprem mais de um fornecedor específico (ENGEL; BLACKWELL; MINIARD, 2009).

\section{Fatores que Infiuenciam no Processo de Decisão de Compra}

No contexto empresarial da atualidade, observa-se que a cultura é um fator que influencia intensamente os hábitos de compra de uma pessoa, tendo em vista que os valores e crenças surgidos em uma sociedade, o ambiente familiar e o convívio em instituições como escola e igreja, contribuem fortemente para a formação dos hábitos de compra. Assim, a cultura é um fator que exerce poderosa influência sobre o comportamento do cliente, por causa dos valores e crenças existentes em um contexto social.

A propósito, Kotler e Keller (2006) ressaltam que a cultura pode ser considerada o principal fator que determina comportamento e desejos de um consumidor, sendo possível compreender a grande influência dos hábitos culturais sobre os indivíduos por meio do entendimento de que a cultura se constitui de subculturas capazes de identificar e socializar seus componentes, a exemplo das nacionalidades, grupos sociais e religiões.

Observa-se que a identificação da cultura e subculturas como fatores determinantes do comportamento do consumidor contribuem para que as organizações identifiquem e ofereçam produtos e serviços adequados ao seu estilo de vida, levando em conta as particularidades percebidas em cada público alvo a ser explorado.

Diante disso, Parente, Limeira e Barki (2009) apontam que fazer com que o consumidor de baixa renda se sinta respeitado é essencial para se garantir espaço nesse mercado. Além disso, em razão do preconceito sofrido pelas classes menos favorecidas, a baixa renda costuma manter sua autoestima elevada (OLIVEIRA; SILVA FILHO, 2013).

No estudo do comportamento do consumidor, os fatores sociais, representados pelos grupos de referência, família, papéis sociais e status, influenciam fortemente a decisão de compra dos indivíduos. Segundo Souza, Farias e Nicoluci (2005), os indivíduos recebem influência direta de grupos de referência de diferentes formas: sendo expostos a comportamentos novos e a diferentes estilos de vida, recebendo influências relativas a autoimagem e atitudes e recebendo pressões sobre a conformidade em relação às regras sociais, fatores que acabam contribuindo para que haja preferência por determinado serviço ou produto.

Para Samara e Morsch (2005), a família seguramente é o grupo de referência mais importante que o consumidor possui. É a organização que mais influencia o comportamento e as decisões de uma pessoa. Schiffman e Kanuk (2009) consideram que a família influencia decisivamente o comportamento 
das pessoas, tendo em vista que é a instituição onde o indivíduo se desenvolve, fazendo parte da formação de sua personalidade, incluindo valores, crenças e atitudes.

Nesse sentido, tais grupos podem exercer influência expressiva de valor, a qual resulta da necessidade de pertencimento dos consumidores ou influência informativa que se materializa quando os consumidores buscam informações sobre produtos/marcas com pessoas confiáveis como amigos, vizinhos, colegas de trabalho, dentre outros (SILVA, 2008).

Outro fator importante no estudo do comportamento do consumidor é o estilo de vida, que evidencia a forma como a pessoa vive e sua trajetória pessoal, além de mostrar as razões que levam consumidores com rendas semelhantes e classe social idêntica a se comportarem de forma totalmente distinta quanto ao que comprar e a maneira de dispor do próprio dinheiro. Ao longo da própria vida, os indivíduos atravessam fases distintas que geram comportamentos de compra diferenciados. Ao longo do tempo verificam alterações nos hábitos e o surgimento de novas expectativas provenientes da maturidade. Existem aspectos pessoais que influenciam mais fortemente a vida das pessoas, como idade e ciclo de vida, ocupação, situação econômica e estilo de vida, personalidade e autoimagem.

Kotler e Armstrong (2008, p. 125) destacam que “o ato de comprar é moldado também pelo estágio do ciclo de vida da família, estágios pelos quais as famílias passam à medida que seus membros amadurecem". Assim, dentre os muitos fatores que influenciam o comportamento de compra do consumidor, o convívio familiar surge como aquele que contribui mais diretamente para a decisão de compra, em função da convivência direta entre as pessoas.

Destaca-se ainda a ocupação e situação econômica que, segundo Kotler e Keller (2006, p. 190), “também influencia o padrão de consumo de uma pessoa". Pode-se inferir, que os produtos ou serviços adquiridos por alguém que exerce uma ocupação simples devem ser também caracterizados pela simplicidade, havendo compatibilidade com os ganhos e com a ocupação, da mesma forma que um funcionário de alto nível adquire produtos e serviços caracterizados pelo luxo e pela riqueza, compatíveis com sua ocupação.

Para Schiffman e Kanuk (2009), a personalidade de uma pessoa é constituída pelas características individuais que a separam das outras. Tais características representam fatores que influenciam o consumidor em seus hábitos de compra e sua identificação permite às empresas colocar seus produtos de maneira mais eficaz em determinados mercados. Segundo Souza, Farias e Nicoluci (2005), os fatores psicológicos apresentados por um cliente podem ter importantes significados em seu comportamento de compra. Assim, fatores como motivação, percepção, aprendizagem e atitudes são muito importantes para a compreensão dos hábitos de compra de uma pessoa. Nesse sentido, a motivação representa um momento de tensão psicológica que precede e prepara a pessoa para agir, ocorrendo a partir do surgimento de uma necessidade, que estimula um fator externo ou interno à pessoa, levando a pessoa a agir após a identificação de uma necessidade, buscando reduzir a tensão, que elimina a referida necessidade inicial.

Para Samara e Morsch (2005), a percepção significa um processo em que as pessoas vivem sensações por meio de mensagens que chamam sua atenção, dentre todas as outras que são apresentadas. Os sentidos humanos correspondem aos estímulos por meio de sensações, que podem ser verificadas em maior ou menor intensidade, dependendo de fatores como o ambiente onde se encontra. Segundo as atitudes são predisposições, sentimentos e tendências relativamente consistentes de um indivíduo em relação a uma determinada situação ou a um objeto. Por ser predisposição para uma ação, a atitude serve de referência para o consumidor avaliar um produto de maneira positiva ou negativa, proporcionando a proximidade ou afastamento do consumidor em relação a este (SOUZA; FARIAS; NICOLUCI, 2009).

\section{Metodologia}

A pesquisa empregou o método quantitativo que frequentemente é aplicado a estudos descritivos com a finalidade de descobrir e classificar as relações entre as variáveis ou averiguar a relação de casualidade entre os fenômenos (RICHARDSON, 1999). Buscou-se para esse estudo uma perspectiva descritiva do tipo levantamento ou survey, por meio de dados coletados de parte da população objetivando uma avaliação da distribuição e inter-relações dos fenômenos que ocorrem naturalmente no ambiente pesquisado (MALHOTRA, 2001).

O questionário para esse estudo foi elaborado levando em consideração as informações obtidas na 
revisão bibliográfica, nos dados secundários obtidos por meio dos relatórios e pesquisa do IBGE, nas escalas identificadas em estudos anteriores. Nesse sentido, considerou-se o agrupamento de assuntos homogêneos, primeiramente, sobre preferência e consumo, a seguir sobre influências ambientais e individuais e, por fim, questões sobre variáveis socioeconômicas e culturais (SILVA, 2008).

Foram entrevistadas 1000 pessoas de ambos os sexos, com idade acima 18, com ocupação profissional identificada, consumidores de baixa renda. O tipo de amostra utilizada foi a não-probabilística por conveniência, em que os entrevistados foram escolhidos por estarem no lugar certo, no momento certo (MALHOTRA, 2001). Apesar das limitações apresentadas, por exemplo, tendenciosidade da coleta e representatividade da população, esse tipo de amostragem é amplamente utilizado em pesquisas, com vantagens relativas ao tempo e ao custo do estudo.

O tratamento dos dados, inicialmente, deu-se no sentido de identificar e analisar missing values (valores perdidos), com a finalidade de identificar algum padrão existente nos dados perdidos que caracterize esse processo. Nessa etapa o pesquisador deve tomar a decisão de ignorar ou não os dados que acontecem aleatoriamente nas variáveis (HAIR, et al., 2009). Vale lembrar que o estudo não apresentou nenhum missing value.

A análise foi feita com o auxílio do Software SPSS 17.0 (Statistical Package for Social Sciences) para análises das técnicas multivariadas e do Software SmartPLS- 2.0, para a análise de equações estruturais. Nesse estudo foram utilizadas técnicas de interdependência, por se tratar de um estudo com uma variável dependente para várias variáveis independentes (AAKER; JOACHIMSTHALER, 2000; HAIR et al., 2009; CORRAR; PAULO; DIAS FILHO, 2009).

Para identificar o formato das distribuições e os padrões de respostas, realizaram-se análises descritivas de média, desvio-padrão, coeficiente de variação, índices de assimetria e curtose dos indicadores propostos para os constructos do estudo. Buscou-se, por meio da análise da matriz de correlação dos indicadores de cada constructo, a colinearidade entre os indicadores. Nesse sentido, considerou-se como sendo uma colinearidade completa coeficientes de correlação iguais a 1 (um), e a inexistência de colinearidade mediante coeficientes de correlação iguais a 0 (HAIR et al., 2009).

Foi utilizada a Análise Fatorial Exploratória (AFE), como forma de avaliação inicial de medida dos constructos e como forma de explicar as variáveis pelas cargas fatoriais para cada fator, já que o pesquisador não conhecia relações de dependência entre as variáveis do estudo. O método utilizado foi o de Componentes Principais (ACP), objetivando a identificação de uma combinação linear entre as variáveis, de forma que o máximo da variância fosse explicado por essa combinação (CORRAR; PAULO; DIAS FILHO, 2009). A confiabilidade das escalas de medidas deuse a partir do cálculo do Alpha de Cronbach, por meio de testes de consistência interna que representa uma medida de intercorrelação existente em um conjunto de itens (HAIR et al., 2009).

Com o objetivo de identificar as relações entre os constructos com o consumo, utilizou-se análise de regressão. Essa técnica possibilita prever o poder de variáveis dependentes (variável prevista ou explicada) em função das variáveis independentes (variáveis explanatórias ou preditoras) possibilitando, também, um poder analítico nas relações entre as variáveis (HAIR et al., 2009). Diante disso, tem-se que a estimativa mais adequada será aquela que apresenta a menor diferença entre os valores reais observados e os valores estimados pelo modelo, ou seja, o menor resíduo ponderado entre todas as observações reais e as estimadas (CORRAR; PAULO; DIAS FILHO, 2009). Buscou-se por meio da análise de regressão um estabelecimento de uma relação funcional entre as variáveis do estudo para a descrição do fenômeno da decisão de compra na baixa renda.

\section{Análise dos dados}

Observou-se uma maior predominância dos entrevistados do gênero masculino, representando $50,5 \%$ da amostra. No que diz respeito à faixa etária dos respondentes, houve uma maior predominância de indivíduos com idade entre os 25 a 30 anos, representando 36,7\% dos entrevistados. Acreditase que o perfil dos respondentes do estudo é jovem já que $82,3 \%$ dos entrevistados têm entre 25 e 44 anos de idade. Em relação ao nível de escolaridade dos pesquisados, obteve-se uma parcela relevante de respondentes com $4^{\text {a }}$ série fundamental, com $(39,7 \%)$, seguido por pessoas com ensino fundamenta completo com $(22,7 \%)$.

A classificação socioeconômica dos respondentes para essa pesquisa teve como foco as classes sociais 
C1, C2, D e E. Percebeu-se uma maior concentração de pessoas nas classes $\mathrm{C} 1$ e $\mathrm{C} 2$, representando $70,7 \%$ da amostra coletada. O tipo de ocupação mais representativa entre os respondentes foi o de trabalhador com habilidades manuais, com 48,8 \% da amostra coletada.

\section{Análise do Constructo Preferência por Marcas}

A avaliação dos indicadores do constructo preferência iniciou-se por meio de uma AFE, utilizando o método de análise de componentes principais, com o objetivo de obter fatores que contivessem o maior grau de explicação da variância possível. Utilizouse o critério de autovalores (Eingenvalues) e do scree plot. Os fatores identificados obtiveram autovalores superiores a 1,000 , com a proposição de três fatores que apresentam uma variância explicada de 78,143\%, agrupando os itens com base na solução apresentada pelo critério de rotação varimax, com o objetivo de maximizar a explicação dos fatores identificados.

Buscou-se, como pressuposto para a utilização de análise fatorial, a colinearidade dos indicadores do constructo preferência por marcas. Percebeu-se que para essa pesquisa as correlações são significativas, no entanto, apresentaram valores abaixo de 0,90 . Foram realizados os testes Kaiser-Meyer-Olkin e o teste de esfericidade de Bartlett's. O primeiro teve o objetivo de medir o grau de correlação parcial entre as variáveis apresentando um resultado de 0,733 . O segundo buscou identificar uma correlação zero entre as variáveis (matriz identidade). $\mathrm{O}$ uso da análise fatorial, para esse estudo, foi validado por meio do teste de esfericidade realizado que apresentou uma significância inferior a 0,05 .

O primeiro fator explicou 41,436\% da variância, o segundo $24,183 \%$ e o terceiro foi responsável por $12,524 \%$ da variância. Realizou-se o cálculo do $A \not p h a$ de Cronbach, com a finalidade de verificar a consistência das escalas. Nesse constructo, obteve-se 0,869 para os doze itens da escala. Tomando-se por base que uma boa consistência se dá a partir de 0,70 , conforme Hair et al. (2009), considera-se que os itens da escala do constructo preferência por marcas, para esse estudo, apresentaram uma consistência satisfatória.

Diante disso, tem-se que o fator 1 (composto pelas variáveis V9, V11, V13, V14 e V17) agrega preferências por marcas que exprimem ousadia/liberdade. Corroborando com os achados, Spink (2012) afirma que a marca tem o poder de legitimar determinadas posições de sujeito, qualificando-o como disposto a enfrentar obstáculos, sedento por aventuras e, por conseguinte, ávido por novas experiências de consumo.

O fator 2 (que faz referência às variáveis V3, V5, V6 e V12), por sua vez, está relacionado à preferência por marcas que apresentam qualidade superior. Neste sentido, a qualidade, além de um alto padrão de desempenho, durabilidade e reconhecimento da marca, permite que se valorize o produto e a sua capacidade de atuação (KELLER, 1993; LAURO, 2000), assim como também possibilita uma (re) afirmação da identidade do consumidor (ROPER et al., 2013).

O fator 3, constituído pelas variáveis V2, V4 e V15, diz respeito à preferência por marcas que expressam confiança. Diante disso, Boecker et al. (2009) apontam que uma marca gera confiança quando oferece $\mathrm{e}$ entrega os benefícios a que se propõe.

A análise fatorial do constructo preferência por marcas, a qual permitiu a discussão acima, é apresentada na tabela 1 a seguir.

Tabela 1 . Análise fatorial exploratória do constructo preferência por marcas

\begin{tabular}{c|c|c|c|l}
\hline & \multicolumn{3}{|c|}{ Componentes } & \multirow{2}{*}{ Comunalidades } \\
\cline { 2 - 4 } & $\mathbf{1}$ & $\mathbf{2}$ & $\mathbf{3}$ & \\
\hline V2 &, 064 &, 139 & $\mathbf{8 4 8}$ &, 742 \\
\hline V3 &,- 144 & $\mathbf{6 5 6}$ &, 607 &, 819 \\
\hline V4 &,- 102 &, 169 & $\mathbf{8 7 1}$ &, 798 \\
\hline V5 &,- 001 & $\mathbf{7 0 8}$ &, 081 &, 508 \\
\hline V6 &, 272 &, $\mathbf{8 4 4}$ &, 255 &, 851 \\
\hline V9 & $\mathbf{9 0 0}$ &, 050 &, 127 &, 829 \\
\hline V11 & $\mathbf{, 8 3 7}$ &, 144 &, 183 &, 747 \\
\hline V12 &, 249 & $\mathbf{8 5 7}$ &, 200 &, 837 \\
\hline V13 & $\mathbf{, 6 4 7}$ &, 565 &,- 276 &, 814 \\
\hline V14 & $\mathbf{9 0 0}$ &, 132 &, 018 &, 827 \\
\hline V15 &, 437 &, 132 & $\mathbf{7 0 4}$ &, 703 \\
\hline V17 & $\mathbf{9 4 2}$ &, 087 &,- 072 &, 900 \\
\hline
\end{tabular}

Fonte: Elaborada pelo autor (2018).

\section{Análise do Constructo Preferência por Locais de Compra}

Buscou-se, como pressuposto para a utilização de análise fatorial, a colinearidade dos indicadores do constructo preferência por locais de compra. Foram 
realizados os testes Kaiser-Meyer-Olkin e o teste de esfericidade de Bartlett's. O primeiro teve o objetivo de medir o grau de correlação parcial entre as variáveis apresentando um resultado de 0,851 . O segundo buscou identificar uma correlação zero entre as variáveis (matriz identidade). A avaliação dos indicadores do constructo preferência por locais de compra iniciou-se por meio de uma AFE, utilizando o método de análise de componentes principais, com o objetivo de obter fatores que contivessem o maior grau de explicação da variância possível. Utilizouse o critério de autovalores (Eingenvalues) e do scree plot. Os fatores identificados obtiveram autovalores superiores a 1,000 , com a proposição de três fatores que apresentam uma variância explicada de 79,818 \%, agrupando os itens com base na solução apresentada pelo critério de rotação varimax, com o objetivo de maximizar a explicação dos fatores identificados.

O primeiro fator explicou 58,653\% da variância, o segundo foi responsável por $11,946 \%$ e o terceiro explicou 9,219\% da variância. Realizou-se o cálculo do Alpha de Cronbach, com a finalidade de verificar a consistência das escalas. Nesse constructo obteve-se 0,869 para os doze itens da escala. Tomando-se por base que uma boa consistência se dá a partir de 0,70 , conforme Hair et al. (2009), considera-se que os itens da escala apresentaram uma consistência satisfatória.

Diante disso, tem-se que o fator 1 agrega as preferências por locais denominados "requintados" (V18, V22, V24, V25 e V27). Isso se justifica em razão de que o ambiente de loja uma importante variável estratégica, posto que pode realçar a qualidade percebida por parte dos consumidores e levar a níveis mais elevados de persuasão (SOLOMON, 2008); além disso ele afeta o tempo percebido e o tempo de estadia no ambiente (BAKER; CAMERON, 1996), auxiliando, portanto, na possibilidade de aumentar os gastos financeiros dos consumidores do lugar.

O fator 2, por sua vez, está voltado para as preferências por locais de compra demarcados pela regionalidade, ou seja, com origem na própria cidade/região (V20, V21, V26 e V28). Neste sentido, Kotler e Keller (2006) afirmam que o fator cultural, marcado aqui pela regionalidade, interfere na preferência de um consumidor por determinado produto ou serviço.

O fator 3 representa as preferências por locais de compra rotineira (V29, V30 e V32). A escolha desses de ambientes de compra está relacionada com a variação da procura (SANTOS, 2009) e essa decisão depende do hábito adquirido e da expectativa de não encontrar maior aglomeração de pessoas (EROGLY; MACHLEIT, 1990).

Tais informações podem ser confirmadas por meio da análise fatorial apresentada na tabela 2.

Tabela 2 . Análise fatorial exploratória do constructo preferência por locais de compra

\begin{tabular}{l|c|c|c|l}
\hline \multirow{2}{*}{} & \multicolumn{3}{|c|}{ Componentes } & \multirow{2}{*}{ Comunalidades } \\
\cline { 2 - 4 } & $\mathbf{1}$ & $\mathbf{2}$ & $\mathbf{3}$ & \\
\hline V18 & $\mathbf{, 7 0 9}$ &, 386 &,- 206 &, 694 \\
\hline V20 &, 416 & $\mathbf{4 9 8}$ &, 405 &, 585 \\
\hline V21 &, 313 & $\mathbf{9 0 3}$ &, 063 &, 917 \\
\hline V22 & $\mathbf{, 7 8 9}$ &, 319 &, 285 &, 806 \\
\hline V24 & $\mathbf{, 8 8 3}$ &, 239 &, 118 &, 851 \\
\hline V25 & $\mathbf{, 8 3 2}$ &, 239 &, 233 &, 804 \\
\hline V26 &, 433 & $\mathbf{6 8 7}$ &, 384 &, 806 \\
\hline V27 & $\mathbf{, 7 0 1}$ &, 236 &, 246 &, 607 \\
\hline V28 &, 265 & $\mathbf{9 1 0}$ &, 105 &, 909 \\
\hline V29 &, 095 &, 079 & $\mathbf{9 1 6}$ &, 854 \\
\hline V30 &, 587 &, 295 & $\mathbf{6 0 1}$ &, 792 \\
\hline V32 &, 235 & $\mathbf{9 3 9}$ &, 115 &, 951 \\
\hline
\end{tabular}

Fonte: Elaborada pelo autor (2018).

\section{Análise do Constructo Influência dos Grupos de Referência}

A avaliação dos indicadores do constructo grupos de referência foi iniciada por meio de uma Análise Fatorial Exploratória (AFE) por meio do método de análise de componentes principais. Utilizouse o critério de autovalores (Eingenvalues) e do scree plot. Os fatores identificados obtiveram autovalores superiores a 1,000 , com a proposição de dois fatores que apresentam uma variância explicada de 70,249\%, agrupando os itens com base na solução apresentada pelo critério de rotação varimax.

O primeiro fator identificado (influência expressiva de valor) foi responsável pela explicação de 54,227\% da variância. $\mathrm{O}$ segundo (influência informativa) foi responsável por $16,022 \%$ da explicação da variância. Diante disso, tem-se que os fatores, juntos, explicam $70,249 \%$ da variância para esse constructo. O cálculo do Alpha de Cronbach, com a finalidade de verificar a consistência das escalas, nesse constructo obteve o resultado de 0,892 para os oito itens da escala. Considerou-se que a consistência dos itens da escala do constructo grupo de referência, para esse estudo é satisfatória (HAIR, et al., 2009). 
Diante disso, tem-se que o fator 1 agrega varáveis que se referem à influência expressiva de valor. Para Silva (2008), esse fator de influência advém da necessidade de pertencimento dos consumidores de baixa renda. Nesse sentido, o indivíduo acha que a compra ou o uso de uma marca melhora a imagem que os outros terão dele e que o uso de determinadas marcas geram respeito e admiração perante os outros consumidores (SOUZA; FARIAS; NICOLUCI, 2005).

O fator 2, por sua vez, está voltado para os grupos que exercem influência informativa. Nesse fator de influência, os indivíduos buscam informações com aqueles que trabalham com o produto como uma profissão ou com amigos, vizinhos, parentes ou colegas de trabalho que tenham informações confiáveis sobre a marca (SILVA, 2008; SAMARA; MORSCH, 2005; SCHIFFMAN; KANUK, 2009).

Esses dados podem ser visualizados na análise fatorial abaixo, conforme tabela 3 .

Tabela 3 . Análise fatorial exploratória do constructo grupos de referência

\begin{tabular}{l|l|c|c|c}
\hline \multicolumn{2}{l|}{} & \multicolumn{2}{|c|}{ Componentes } & \multirow{2}{*}{ Comunalidades } \\
\cline { 3 - 4 } \multicolumn{2}{l|}{ V33 } & $\begin{array}{l}\text { Busco } \\
\text { experiência e } \\
\text { conhecimento } \\
\text { com amigos, } \\
\text { vizinhos, } \\
\text { parentes } \\
\text { ou colegas } \\
\text { de trabalho } \\
\text { que têm } \\
\text { informações } \\
\text { confiáveis } \\
\text { sobre locais } \\
\text { de compra }\end{array}$ &,- 133 &, 514 \\
\hline V34 & $\begin{array}{l}\text { As } \\
\text { observações } \\
\text { de especialistas } \\
\text { influenciam a } \\
\text { minha escolha } \\
\text { por locais de } \\
\text { compra }\end{array}$ &, 265 &, 781 &, 681 \\
\hline
\end{tabular}

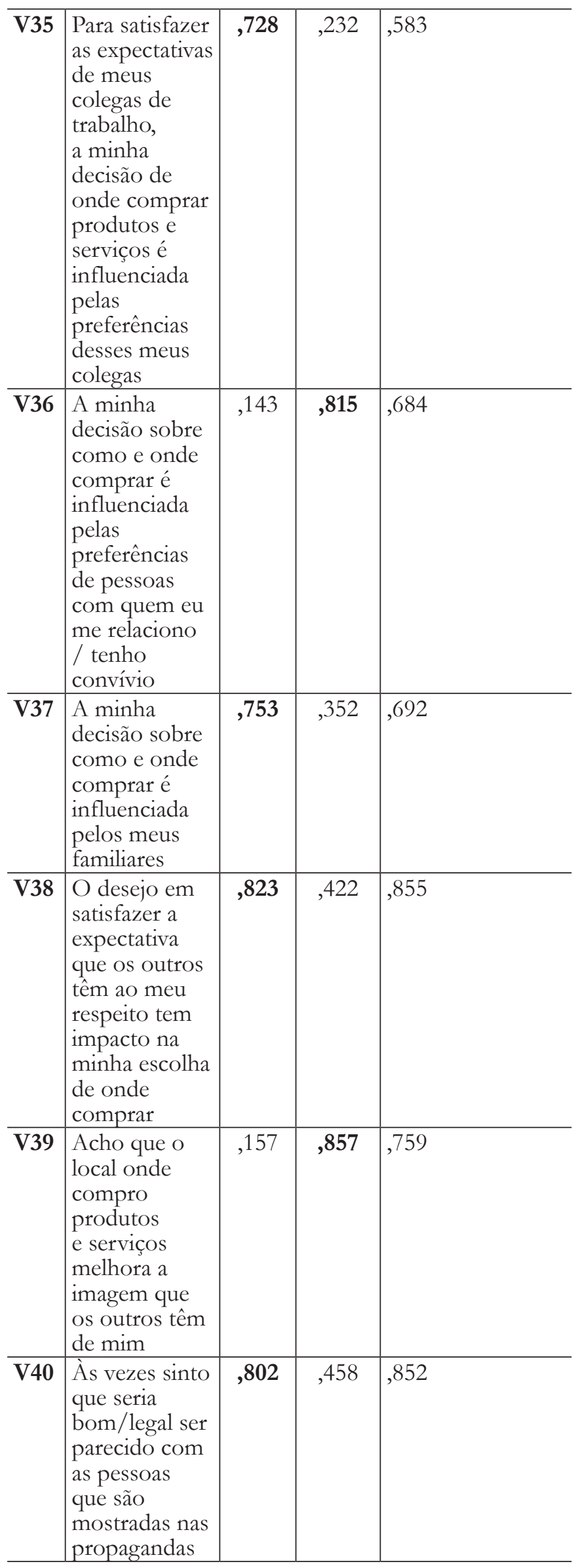

Fonte: Elaborada pelo autor (2018). 


\section{Análise do Constructo Valores}

Percebeu-se que, para essa pesquisa, as correlações do constructo valores são significativas, no entanto, apresentaram valores abaixo de 0,90 . Foram realizados os testes Kaiser-Meyer-Olkin e o teste de esfericidade de Bartlett's. O primeiro, com o objetivo de medir o grau de correlação parcial entre as variáveis apresentando um resultado de 0,585 . De acordo com esse resultado apresentado, explica-se a variação dos dados originais de uma maneira satisfatória.

A avaliação dos indicadores do constructo valores foi iniciada por meio de uma Análise Fatorial Exploratória (AFE) por meio do método de análise de componentes principais. Utilizou-se o critério de autovalores (Eingenvalues) e do scree plot. Os fatores identificados obtiveram autovalores superiores a 1,000, com a proposição de dois fatores que apresentam uma variância explicada de 45,634\%, agrupando os itens com base na solução apresentada pelo critério de rotação varimax.

O primeiro fator identificado explicou de $26,922 \%$ da variância. O segundo foi responsável por $18,712 \%$ da explicação da variância. O cálculo do $A \not h h a$ de Cronbach, com a finalidade de verificar a consistência das escalas, nesse constructo obteve o resultado de 0,752 para os oito itens da escala. Considerou-se que a consistência dos itens da escala do constructo grupo de referência, para esse estudo é baixa (HAIR, et al., 2009).

Diante disso, tem-se que o fator 1 agrega as valores relacionados ao respeito. Compreende-se, deste modo, que fazer com que o consumidor se sinta respeitado constitui requisito fundamental para o sucesso no mercado da base da pirâmide (PARENTE; LIMEIRA; BARKI, 2009).

O fator 2, por sua vez, está voltado para os valores da autoestima. Corroborando com os achados, Oliveira e Silva Filho (2013) afirmam que os consumidores de baixa renda se preocupam em manter a autoestima elevada em detrimento do preconceito que as classes menos favorecidas sofrem.

As informações da análise fatorial do constructo valores podem mser visualizadas abaixi, conforme a tabela 4.
Tabela 4 . Análise fatorial exploratória do constructo valores

\begin{tabular}{|c|c|c|c|c|}
\hline & \multicolumn{2}{|c|}{ Componentes } & \multirow[t]{2}{*}{ Comunalidades } \\
\hline & & 1 & 2 & \\
\hline V44 & $\begin{array}{l}\text { Ter uma } \\
\text { vida cheia de } \\
\text { atividades }\end{array}$ & 204 & ,245 &, 715 \\
\hline V45 & $\begin{array}{l}\text { Ter uma vida } \\
\text { emocionante }\end{array}$ &,- 057 & ,342 & 693 \\
\hline V46 & $\begin{array}{l}\text { Ter bom } \\
\text { relacionamento } \\
\text { com outras } \\
\text { pessoas }\end{array}$ & ,768 & ,060 & 816 \\
\hline V47 & $\begin{array}{l}\text { Vencer por } \\
\text { mérito próprio }\end{array}$ & 101 & 874 & ,780 \\
\hline V48 & Ser respeitado & ,804 &, 000 & ,688 \\
\hline V50 & Ter segurança &,- 062 & ,077 &, 719 \\
\hline V51 & \begin{tabular}{|l} 
Ter \\
autorespeito, \\
respeito \\
próprio
\end{tabular} & 898 & ,076 & 814 \\
\hline V52 & $\begin{array}{l}\text { Ter o } \\
\text { sentimento } \\
\text { de realização } \\
\text { pessoal }\end{array}$ & ,094 & ,863 & 833 \\
\hline
\end{tabular}

Fonte: Elaborada pelo autor (2018).

\section{Análise do Constructo Preço, Qualidade dos produtos, Atendimento e Marca}

As correlações do constructo preço, qualidade dos produtos, atendimento e marca, para essa pesquisa, não são significativas apresentando valores bem abaixo de 0,90. A partir do teste Kaiser-Meyer-Olkin, que para esse constructo apresentou um resultado de 0,528 , mediu-se o grau de correlação parcial entre as variáveis. De acordo com esse resultado apresentado, explica-se a variação dos dados originais de uma maneira aceitável. O uso da análise fatorial, para esse estudo, foi validado por meio do teste de esfericidade realizado, que apresentou uma significância inferior a 0,50 .

O fator identificado obteve autovalores superiores a 1,000, apresentando uma variância explicada de $61,616 \%$ dos indicadores, reunindo os itens com base na solução dada pelo critério de rotação varimax, com o fito de maximizar a explicação dos fatores identificados.

A análise fatorial do constructo identidade apresentou dois fatores, com uma variância total explicada de $61,616 \%$. Observou-se que para esse constructo, todas as comunalidades apresentaram níveis insignificantes, sendo que as variáveis V56 e V57 (Atendimento e 
Marca, respectivamente) com resultados de 0,704 e 0,746 foram as mais significativas, conforme a tabela 5.

Tabela 5 . Variância total explicada do constructo preço, qualidade dos produtos, atendimento e marca

\begin{tabular}{|c|c|c|c|c|}
\hline & \multicolumn{2}{|c|}{ Componentes } & \multirow[t]{2}{*}{ Comunalidades } \\
\hline & & 1 & 2 & \\
\hline V54 & Preço & ,686 &,- 052 & ,473 \\
\hline V55 & \begin{tabular}{|l|} 
Qualidade \\
dos produtos
\end{tabular} & ,736 & ,003 & ,542 \\
\hline V56 & Atendimento & ,469 & ,696 & ,704 \\
\hline V57 & Marca &,- 366 & ,782 & ,746 \\
\hline
\end{tabular}

Fonte: Elaborada pelo autor (2018).

\section{Avaliação do Modelo Estrutural}

Com a finalidade de avaliar o modelo teórico a ser testado, foi utilizada a modelagem de equações estruturais com o uso da técnica PLS - Partial Least Square por meio do software Smartpls - 2.0. Para cada constructo, considerou-se a análise fatorial exploratória realizada, mediante o agrupamento dos indicadores em cada fator, em função das significâncias das cargas fatoriais, da comunalidade explicada e dos procedimentos relativos ao uso estatístico do Alpha de Cronbach. Dessa maneira, cada fator de $1^{a}$ ordem foi ligado às variáveis observadas e os constructos de $2^{\mathrm{a}}$ ordem foram relacionados aos de $1^{\mathrm{a}}$ ordem.

Uma análise fatorial confirmatória foi realizada com a finalidade de analisar cada constructo separadamente. Os critérios da análise foram: os coeficientes de cada path, o Alpha de Cronbach, validade convergente e Variância Extraída (AVE). Os parâmetros aceitos na literatura são que as cargas fatoriais e a confiabilidade devem apresentar níveis acima de 0,7 e a variância explicada deve apresentar níveis acima de 0,5 (CHIN, 2010).

O modelo inicial do estudo apresentou uma relação de dependência entre o consumo baixa renda e as variáveis independentes preferências por locais de compra, valores, preferências por marcas, grupos de referência, percepção em relação à marca, atendimento, preço e qualidade dos produtos, conforme a figura 3.
Figura 3 . Modelo inicial do estudo

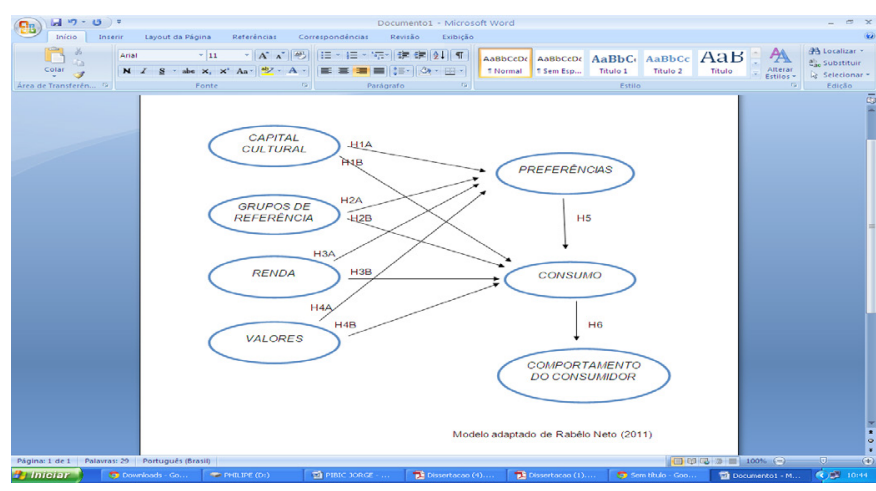

Fonte: Elaborada pelo autor (2017).

A análise do modelo definitivo da pesquisa demonstrou que o consumo de produtos por consumidores de baixa renda está diretamente relacionado à influência da preferência por locais de compra e preferência por marcas, conforme os índices apresentados de 0,363 e 0,564 respectivamente. Notou-se, então, que o consumo de baixa renda é explicado em 36,3\% pelos locais de compra e em $56,4 \%$ pela preferência por marcas.

A preferência por locais de compra é influenciada pelos valores em 0,210 , e pelos grupos de referência em 0,494. Diante disso, a partir do resultado apresentado de 0,963 , notou-se que a preferência é explicada em $96,3 \%$ pelos constructos analisados.

Tem-se que a preferência por locais de compra e por marcas são antecedentes influenciadores do consumo de baixa renda para esse estudo. Observou-se, assim, que os locais de compra e as marcas são fatores determinantes no processo de decisão de compra de consumidores de baixa renda.

\section{Considerações Finais}

A análise descritiva dos dados e as questões relacionadas ao perfil demográfico dos consumidores de produtos culturais de baixa renda apresentaram predominância de alguns aspectos relacionados aos respondentes do estudo. Desse modo, observouse uma maior predominância dos entrevistados do gênero masculino, representando 50,5\% da amostra. Houve uma maior predominância de indivíduos com idade entre os 25 e 44 anos, representando $82,3 \%$ dos entrevistados.

Em relação ao nível de escolaridade dos pesquisados, obteve-se uma parcela relevante de respondentes da $4^{\mathrm{a}}$ 
série fundamental com $(39,7 \%)$, seguido por pessoas com ensino médio completo com $(22,7 \%)$. Pode-se dizer que o perfil de idade escolhido para o estudo poderia explicar essa ocorrência de dados. Percebeuse uma maior concentração de pessoas nas classes C1, C2 e D, representando $94,2 \%$ da amostra coletada. Esse resultado pode ser explicado por meio do método utilizado para o controle da coleta amostral. O tipo de ocupação mais representativa entre os respondentes foi a de trabalhador com habilidades manuais com $48,8 \%$ da amostra coletada.

O objetivo geral da pesquisa que foi analisar o perfil dos consumidores de baixa renda a partir das variáveis que influenciam o processo de decisão de compra desses consumidores foi alcançado mediante o modelo testado que integrou os antecedentes de consumo identificados na literatura decorrentes, principalmente, de pesquisas qualitativas e analisados isoladamente. Desse modo, fez-se uma análise fatorial confirmatória para a confirmação da validade e da confiabilidade do modelo testado. Nesse sentido, os valores acima de 0,7 são satisfatórios para a confiabilidade.

A verificação do modelo demonstrou que o constructo preferência por locais de compra recebe influência dos seguintes constructos, por ordem de significância: valores $(0,210)$ e grupos de referência $(0,494)$. A preferência por marcas recebe influência dos constructos: grupos de referência $(0,392)$, valores $(0,445)$ e percepção preço, marca, qualidade dos produtos e atendimento $(0,202)$. Assim, o modelo apresentou dois antecedentes para o consumo de baixa renda: preferência por locais de compra com $36,3 \%$ de contribuição para o modelo e preferências por marcas com $56,4 \%$ de contribuição.

A principal contribuição teórica desta pesquisa foi a utilização de métodos quantitativos para analisar o tema estudado, utilizando-se de análise multivariada de dados e de modelagem de equações estruturais. Os resultados apontam para um perfil de consumidores de baixa renda onde os locais de compra e as marcas são marcadores relevantes no processo de decisão de compra. Assim, as informações formuladas a partir desse estudo são necessárias para dar a sustentabilidade necessária às decisões gerenciais tendo como objetivo central satisfação e/ou fidelização do consumidor de baixa renda.

No que diz respeito às limitações do estudo, o corte transversal único utilizado no estudo, devido às suas restrições metodológicas nas inferências em relações causa e efeito, é considerado uma limitação da pesquisa, quando comparado a pesquisas experimentais. No entanto, buscou-se minimizar essa limitação por meio das hipóteses identificadas na literatura. O procedimento amostral, apesar de representativo da população, apresenta limitações na extrapolação dos dados, sob rigor estatístico, em função de o procedimento realizado ser não-probabilístico. A pesquisa apresenta, ainda, como limitação a ausência de um grupo de controle.

A partir da presente pesquisa, emergem oportunidades de estudos futuros. A saber: (a) replicar a presente pesquisa com a utilização de uma amostragem probabilística com a finalidade de obter uma extrapolação dos dados para a população; (b) integração, ao modelo testado, de variáveis individuais que não foram testadas, como por exemplo, atitude do consumidor, percepção e envolvimento do consumidor; (c) inserção de variáveis de controle ao modelo testado; d) Utilização do modelo testado nessa pesquisa com outros perfis de consumidores.

\section{Referências}

AAKER, D.; JOACHIMSTHALER, E. Como construir marcas líderes. São Paulo: Futura, 2000.

\section{ABEP. CCEB - Critério de Classificação}

Econômica Brasil. São Paulo: ABEP, 2011.

ASSOCIAÇÃO PAULISTA DE FUNDAÇÕES. $9^{\circ}$ Encontro Paulista de Fundações $-3^{\circ}$ painel: Pesquisa Data Popular/APF - O novo Brasil e o protagonismo cidadão: oportunidades no terceiro setor - Renato Meirelles, 2015. Disponível em: <http://www. apf.org.br $/$ fundacoes $/$ index.php?option $=\mathrm{com}_{-}$ content\&view $=$ article\&id $=1969: 9-$ encontro-paulistade-fundacoes-3-painel-pesquisa-data-popular-apfo-novo-brasil-e-o-protagonismo-cidadao-oportunidades-no-terceiro-setor-renato-meirelles\&catid=19:da tashows\&Itemid $=172>$. Acesso em: 20 de outubro de 2017.

BARROS, C; ROCHA, E. Lógica de consumo em um grupo das camadas populares: Uma visão antropológica de significados culturais. Rio de Janeiro: ANPAD, 2007.

BAKER, J. A ; CAMERON, M. The effects of the service environment on affect and consumer perception of waiting time: an integrative review 
and research propositions. Academy of Marketing Science Journal, v. 24, n. 4, p. 338-349, 1996.

BOECKER, G. et al.. Consumer valuation of functional foods and nutraceuticals in Canada: A conjoint study using probiotics, Appetite, v. 52, n. 2, pp. 257-265. 2009.

CASTILHOS, R. B. Subindo o morro: consumo, posição social e distinção entre famílias de classes populares. XXXI Encontro da ANPAD. Rio de Janeiro, 22-26 Set, 2007.

CHIN, W. W. How to write up and report PLS analyses. In: ESPOSITO VINZI, V.; CHIN, W. W.; HENSELER, J.; WANG, H. (eds.) Handbook of Partial Least Squares: Concepts, Methods and Applications in Marketing and Related Fields, pp. 655690. Springer, Berlin, Germany, 2010.

CORRAR, J.; PAULO, E.; DIAS FILHO, J. (Coords.). Análise multivariada: para os cursos de administração, ciências contábeis e economia / FIPECAPI - Fundação Instituto de Pesquisas Contábeis, Atuariais, Financeiras. São Paulo: Atlas, 2009.

DIAS, S. R. (Coord.) et al.. Gestão de Marketing: professores do Departamento de Mercadologia da FGV-EAESP e convidados. São Paulo: Saraiva, 2003.

EHRENBERG, A. S. C.; GOODHART, G. J.; BARWISE, T. P. Double Jeopardy revisited. Journal of Marketing, v. 54, p. 82-91, 1990.

ENGEL, J. F.; BLACKWELL, R. D.; MINIARD, P. W. Comportamento do consumidor. São Paulo: Pioneira Thomson Learning, 2009.

EROGLY, S.; MACHLEIT, K. An empirical study of retail crowding: antecedents and consequences. Journal of Retailing, v. 66, n. 2, pp. 201-221, 1990.

HAIR, J. et al.. Análise Multivariada de Dados. Tradução Adonai Schlup Sant Ánna e Alselmo Chaves Neto. 6. ed. Porto Alegre: Bookman, 2009.

KELLER, K. L. Conceptualizing and Measuring Consumer-Based Brand Equity. Journal of Marketing, v. 57, p. 1-22, 1993.

KOTLER, P. A sociedade do sonho: Comunicação, cultura e consumo. 2. ed. Rio de Janeiro: Mauad, 1995.
KOTLer, P.; ARMStrong, G. Princípios de Marketing. São Paulo: Pearson Prentice Hall, 2008.

KOTLER, P.; KELLER, K. L. Administração de marketing. 12 ed. São Paulo: Pearson Prentice hall, 2006.

SILVA, A. L. L. Consumo de produtos culturais em São Paulo: Análise dos fatores antecedentes e proposta de Modelo. 2008. Tese (Doutorado) Universidade de São Paulo-USP, São Paulo, 2008.

MALHOTRA, N. Pesquisa de Marketing. 3. ed. Porto Alegre: Bookman, 2001.

MATSUYAMA, K. The rise of mass consumption societies. Journal of Political Economy, Chicago, v. 110, n. 5, 2002.

OlIVEIRA, S. R. G.; SILVA FILHO, E. P. Comportamento de Consumo das Mulheres de Baixa Renda: Estudo com Serviços de Tratamento Capilar em Salões de Beleza. PMKT - Revista Brasileira de Pesquisas de Marketing, Opinião e Mídia, v. 13, pp. 167-185, Outubro, 2013.

PARENTE, J. Varejo no Brasil: Gestão e Estratégia. São Paulo: Atlas, 2000.

PARENTE, J.; LIMEIRA, T.; BARKI, E. Varejo para a Baixa renda. Porto Alegre: Bookman, 2008.

PARENTE, J.; SILVA, H. M. R. O mercado de baixa renda em São Paulo: um estudo de segmentação baseado no orçamento familiar. XXXI Encontro da ANPAD, 2007.

PEREZ, C.; BAIRON, S. Universos de sentido da população de baixa renda no Brasil: semânticas da estabilidade, da ascensão social e da mobilidade. Revista Matrizes, Ano 7, n. 2 jul./dez. 2013.

PINTO, A.; FREDES, C.; MARINHO, L. C. Curso de economia - elementos de teoria econômica. Rio de Janeiro: Unilivros, 1983.

PRAHALAD, C.K. A riqueza na base da pirâmide. São Paulo: Bookman, 2005.

RABÊLO NETO, A. Variáveis influenciadoras no consumo de produtos culturais: um estudo com consumidores de baixa renda. 2011. 175 p. Dissertação (Mestrado em Administração de Empresas) - Universidade de Fortaleza - UNIFOR, PPGA, Fortaleza, 2011. 
REDMOND, W. H. Exploring limits to material desire: the influence of preferences vs. plans on consumption spending. Journal of Economic Issues, v. 35, n. 3, 2001.

RICHARDSON, R. Pesquisa social: métodos e técnicas. 3. ed. São Paulo, Atlas, 1999.

ROCHA, A. da; SILVA, J. da. Inclusão social e marketing na base da pirâmide: uma agenda de pesquisa, RAE-eletrônica, v. 7, n. 2, Art. 23, jul./dez. 2008.

ROPER, S. et al.. Constructing luxury brands: exploring the role of consumer discourse. European Journal of Marketing, v. 47, n. 3/4, p. 375-400, 2013.

ROSSETTI, J. Introdução à eco-economia. 15. ed. São Paulo: Atlas,1991.

SAMARA, B. S.; MORSCH, M. A. Comportamento do consumidor: conceitos e casos. São Paulo: Prentice Hall, 2005.

SANTOS, F. Hábitos de compras e uso de lista de compras. Rev. Portuguesa e Brasileira de Gestão, v.8, n.1, Lisboa, mar., 2009.

SCHIFFMAN,L.G.;KANUK,L.L.Comportamento do consumidor. Rio de Janeiro: LTC, 2009.

SHETH, J.; MITTAL, B.; NEWMAN, B. Comportamento do cliente: Indo além do comportamento do consumidor. São Paulo: Atlas, 2001.

SOLOMON, M. R. Consumer behavior: buying, having, and being. 11. ed. New Jersey: Prentice Hall, 2014.

O Comportamento do Consumidor: comprando, possuindo e sendo. 7. ed. Porto Alegre: Bookman, 2008.

SOUZA, A. R. C; FARIAS, J. M. P; NICOLUCI, T. C. Principais Fatores que Influenciam os Consumidores Universitários a Frequentarem Bares Noturnos na Cidade de Presidente Prudente. 2005. Monografia (Grau de Bacharel em Administração). Faculdade de Ciências Econômicas e Administrativas de Presidente Prudente. Faculdades Integradas "Antônio Eufrásio de Toledo". Presidente Prudente, 2005.
SPINK, M. J. Aventura, Liberdade, Desafios, Emoção: os tons do apelo ao consumo do risco-aventura. Revista de Ciências Sociais, n. 37, pp. 45-65, Out. 2012.

STEFANO, F.; SANTANA, L.; ONAGA, M. O retrato dos novos consumidores brasileiros, Exame, v. 42, n. 7, p. 20-30, Abr. 2008.

ZEITHAML, V.; BITNER, M. Marketing de serviços: a empresa com foco no cliente. Porto Alegre: Bookman, 2003. 